\title{
THE PROCESS OF HATCHING IN CORYDALIS CORNUTA LINN.
}

\author{
Roger C. Smith, Ph. D., \\ U. S. Entomological Laboratory, Charlottesville, Va.
}

A study of the manner of hatching of Corydalis cornuta was made to ascertain if there were an egg burster used. Dr. C. V. Riley (1876) stated in his observations on the life history of Corydalis cornuta Linn that "the egg burster* has the form of the common immature mushroom and is easily perceived on the end of the vacated shell." This note was repeated in his ninth annual Missouri Report, $1877^{\circ}$ (p. 127). This is the only published account of hatching known to the writer, but in part has been quoted by many writers since its appearance. Through the kindness of Professor A. N. Caudell, of the National Museum, an abundance of preserved material was made available for study. Throughout the month of July of the current year, a large number of egg masses of Corydalis cornuta were found along a small stream near this laboratory on rocks in the stream and on several overhanging trees. Some were taken to the laboratory and observed for hatching.

There appears to be no doubt that Professor Riley misinterpreted a rather unusual shaped micropyle (Fig. 1) for an egg burster as suggested by Davis (1903). This micropyle, as is generally the case, is located at one end of the elliptical egg and in the Sialidæ, to which Corydalis belongs, has somewhat the shape of certain mushrooms in the button stage. It is attached to the exterior of the chorion and not to an inner structure as might be expected if it were an egg burster. It was not observed to serve any purpose whatsoever in hatching.

Professor Riley states further that egg bursters are generally if not always a part of the ambion (amnion, perhaps). This until relatively recently, perhaps to Heymon's work, 1906, appears to have been the prevailing opinion concerning egg bursters and we find in literature statements many times regarding the molting of the amnion at hatching.

* I am not aware that this special structure has been named. It is generally if not always, a part of the ambion, and common to many insects, though varying much in form. It may be known as the ruptor ovi. Dr. Hagen has called it the "egg burster," while erpetologists designate as "egg tooth," a structure having the same purpose. 
Heymons (1906) states that the egg burster of the Pentatomidx is a thickening and specialization of the embryonic cuticula. This cuticula is a very thin delicate structure undoubtally rudimentary. It is molted at hatching and with it goes the egg burster. The writer has investigated the egg burster in the Chrysopidæ. It likewise is a specialized chitinous apparatus situated on the thin embryonic cuticula and the whole is shed at hatching. The molt was observed to withst and the action of heated caustic potash without injury and is undoubtedly chitinous. The writer concluded from a rather
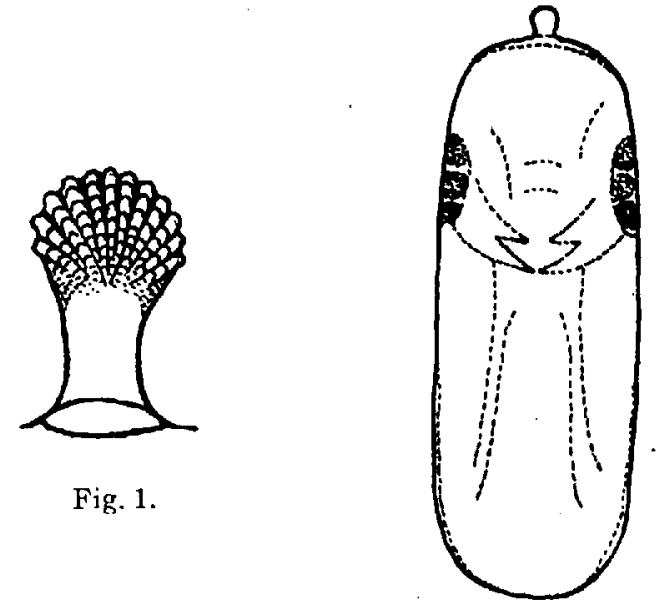

Fig. 2.

Fig. 1. A micropyle of an egg of Corydalis cornuta highly magnified.

Fig. 2. Ventral aspect of an egg of Corydalis cormuta ready to hatch. Note the large mandibles, the two ocellar fields and the absence of an egg burster in the mid ventral cephalic region.

brief study of the embryology of the Chrysopidæ that the amnion was ruptured during the development of the embryo and was drawn into the mid-intestine with the last of the yolk to disintegrate or be absorbed. So the statement that they are generally if not always on the amnion can not be accepted in the light of later research. All egg bursters so far recorded are on a chitinous embryonic cuticula, which in most cases is shed at hatching as for example in the Chrysopidæ, Hemerobiidæ, Pentatomidæ, Trichoptera and the Psocidæ. Lepisma and the Pulicidæ are said to retain the egg bursters for a day or longer, 
but no recent accounts have been given of this fact in either case. In Corydalis cornuta there is an embryonic molt, but a careful study of the same has not revealed any structure that might serve as an egg burster. Furthermore, the process of hatching gives no indication of the use of any such structure. On the other hand, hatching is effected by a means none the less interesting and perhaps unusual.

When egg masses of Corydalis cornuta are cut or scraped from their substratum, some eggs which are ready to hatch will often hatch in a short time, so that hatching may be readily observed. Frequently eggs that are ready to hatch, judging from external appearances, may hold over for several days. The hatching process proceeds rather slowly and varies in the length of time between stages. Eggs ready to hatch are smoky gray, often reddish or pinkish in the lower three-fourths and lighter gray anteriorly. On the venter of the egg, the amber colored bifid mandibles can be seen about one-third the distance from the anterior end of the egg (Fig. 2). At the sides can be plainly. seen the two large black eye spots or ocellar fields, each with seven ocelli. The head of the embryo is therefore bent caudo-ventrad with the prothorax beneath the micropylar area.

Usually the first visible evidence of hatching is slight movements of the embryo. Under highest power binocular, air bubbles will be seen to be slowly going down the pharynx. As this continues the anterior region of the egg becomes perceptibly dilated. The chorion shrinks slightly as the air within is withdrawn until it becomes rather closely appressed to the embryo, suggesting premolting conditions. The contour of the embryo can now be plainly seen, the large head being very evident. The egg becomes asymetrical, due to the enlargement anteriorly and the shrinkage around the abdomen posteriorly. As the swallowing of air bubbles continues, the embryo exerts considerable additional pressure by pushing itself upward. The chorion over the anterior end of the egg becomes tightly stretched under the increasing internal pressure and finally gives way, providing the opening for the emergence of the larva. The rent is usually small at first and difficult to see, but soon increases to accommodate the large head of the embryo. In no case did the mandibles pierce the chorion to 
start the rent. The embryo pushes itself feebly upward, the dorsum of the head first appearing. This upward shifting continues until the sixth or seventh abdominal segment is reached. During the emergence the swallowing of air bubbles increases in rate. The embryo normally stops at this stage of emergence for a varying period of time. It now casts off the embryonic molt in precisely the same way as hatching is effected. By continued swallowing of air the old cuticula is stretched further. Finally the swallowing of air bubbles is discontinued and the larva begins to work the abdomen forward as is done in many insects at molting. As the abdomen is brought forward within the old cuticula the thoracic region becomes greatly strained and finally tears over the prothorax. Immediately the broad, somewhat angular prothorax appears. The setae straighten up as the smooth glassy coat slips back. The thorax is slowly pushed through the rent. The molt is held back by the mouth parts causing the head to be turned ventrad so that the larva forms a loop over the egg.

The heavy chitinous mandibles and abdominal hooks are not shed as might be expected. This thin embryonic cuticula resembles more a tight fitting sack than a true molt. It is probably not attached (or is very loosely attached) to the inside of the chorion at some place as in the Chrysopidæ and Pentatomidæ for many embryos in confinement tumble from the egg and fail to cast this embryonic molt. All such larvæ died. The legs before shedding this molt are useless and the lateral abdominal filaments are bound close to the body. After the molt the larvæ are very active and the filaments expand to their normal position. This molt lies normally in the rent of the egg shell.

The writer concludes that hatching and the first molt are effected by the swallowing of air bubbles combined with the upward pushing of the embryo. The rent in the chorion is at the anterior end generally at one side of the micropyle. If the empty chorion be mounted and examined microscopically it will be seen that the rent is generally ragged and has the appearance of being torn by internal pressure. Sometimes the entire upper end of the egg is torn off as if it were a cap.

The phenomenon of swallowing air bubbles to effect hatching and molting has been recorded several times in literature. 
Kunckel (1890) pointed out that nymphs of the Acridelideidæ accumulated air in their crops, causing the "ampoule cervicale" of each to become dilated which in turn raised the lids of their earthen cases. He states further that the swallowing of air bubbles is the chief means of molting. Peyerimhoff (1901) states that the embryos of the Psocids regularly swallow air bubbles to increase their size and enable them to exert the necessary pressure at hatching. This writer also gives a brief summary to date of the literature on the point. Heymons (1906) has noted the increase in size of Pentatomid nymphs at hatching by taking in air and adds that Foriculidæ do likewise at molting and hatching. The phenomenon is perhaps more common than a bibliography indicates.

\section{BIBLIOGRAPHY.}

Riley, C. V. 1876. On the curious egg mass of Corydalus cornutus (Linn.) In Proc. Amer. Ass. for Advancement of Science. V. 25, p. 275-279.

1877. The Hellgrammite. Corydalus cornutus (Linn.) In 9th Ann. Rept. of Noxious, Beneficial, and other Insects of Mo., p. 125-129.

Kunckel d'Herculais, J. 1890. Du rôle de l'air dans le mécanisme physiologique de l'éclosion, des mues et de la métamorphose chez les insectes Örthoptères. de la famille des Acridides. In Comptes Rendus de 1'Académic des Sciences, V. 110 , p. $807-809$.

Peyerimhoff, Paul de. 1901. I.e mécanisme de l'éclosion chez les Psoqucs, In Ann. Soc. Ent. de France, V. 70, p. 149-152.

Davis, K. C. 1903. Sialididae of North and South America. In Aquatic Insects in N. Y. State. N. Y. State Museum, Bul. 68, pt. 7, p. 442-487.

Heymons, Richard. 1906. Utber einer Apparat zum Öffnen der Eischale bei den Pentatomiden. In Zeitschr. Wiss. Insektenhiologie. V. 2, p. 73-\$2. 